\title{
Development of New Antithrombotic Regimens for Patients with Acute Coronary Syndrome
}

\author{
Sudhakar George ${ }^{1} \cdot$ Eunice N. C. Onwordi $^{2} \cdot$ Amr Gamal $^{3} \cdot$ Azfar Zaman $^{3}$
}

Published online: 11 April 2019

(c) The Author(s) 2019

\begin{abstract}
Patients with acute coronary syndrome (ACS) require long-term antithrombotic intervention to reduce the risk of further ischemic events; dual antiplatelet therapy with a $\mathrm{P}_{2} \mathrm{Y}_{12}$ inhibitor and acetylsalicylic acid (ASA) is the current standard of care. However, pivotal clinical trials report that patients receiving this treatment have a residual risk of approximately $10 \%$ for further ischemic events. The development of non-vitamin K antagonist oral anticoagulants (NOACs) has renewed interest in a 'dual pathway' strategy, targeting both the coagulation cascade and platelet component of thrombus formation. In the phase III ATLAS ACS 2 TIMI 51 trial, a 'triple therapy' approach (NOAC plus dual antiplatelet therapy) showed reduced ischemic events with rivaroxaban $2.5 \mathrm{mg}$ twice daily, albeit at an increased risk of bleeding. Two studies have investigated the role of NOACs in combination with a $\mathrm{P}_{2} \mathrm{Y}_{12}$ inhibitor, with or without ASA, in reducing bleeding risk in patients with atrial fibrillation undergoing percutaneous coronary intervention; two further studies are underway. Although these trials will help to inform optimal treatment protocols for secondary prevention of ACS, an individualized approach to treatment will be needed, taking account of the high frequency of co-morbid conditions found in this patient population.
\end{abstract}

\section{Key Points}

Dual antiplatelet therapy with a $\mathrm{P} 2 \mathrm{Y}_{12}$ inhibitor and acetylsalicylic acid is the current standard of care for patients with acute coronary syndrome; however, a residual risk of approximately $10 \%$ for recurrent ischemic events and death persists.

Triple therapy with a non-vitamin $\mathrm{K}$ antagonist oral anticoagulant (NOAC) plus dual antiplatelet therapy reduces the risk of ischemic events, albeit at an increased risk of bleeding.

Studies are now focused on dual targeting of platelet and thrombin activation pathways with a NOAC plus single antiplatelet therapy.

Azfar Zaman

azfar.zaman@nuth.nhs.uk

1 Keele Cardiovascular Research Group, Institute for Applied Clinical Science and Centre for Prognosis Research, Institute of Primary Care and Health Sciences, Keele University, Keele, UK

2 Queen Alexandra Hospital, Portsmouth, UK

3 Department of Cardiology, Freeman Hospital, Newcastle University, Newcastle upon Tyne, UK

\section{Introduction}

Admissions for acute coronary syndrome (ACS) in the USA accounted for $>1.3$ million unique hospitalizations in 2006, with annual costs estimated at US\$54,821 per patient [1]. Rehospitalization with a cardiovascular diagnosis cost an average of US $\$ 9510$ per patient, with $30 \%$ of patients rehospitalized at least once within the first 12 months after index ACS admission. In Europe, hospital discharge rates for coronary heart disease per 100,000 population increased from 532 in 2001 to 608 in 2012 [2], and the estimated annual cost (2004) per patient with ACS ranges from $€ 7009$ (UK) to $€ 12,086$ (Italy). The largest contributor to total costs was hospital stay [3].

Despite optimal standard care and secondary prevention, patients remain at high risk of further ischemic coronary events and death in the months and years after an index ACS event $[4,5]$. This article examines a 'dual antiplatelet' approach for secondary prevention in patients with ACS and explores the evidence base for a 'dual strategy' approach in this setting. 


\section{Antithrombotic Approaches to Secondary Prevention}

Thrombus formation after atherosclerotic plaque rupture involves both platelet activation and fibrin generation (Fig. 1) [6, 7]. Furthermore, elevated thrombin generation persists long after the index ACS event [8], supporting longterm risk-reduction strategies [5]. Platelet activation and coagulation are highly interdependent processes. Thrombin is central to both, by stimulating platelet activation and aggregation and catalyzing fibrinogen conversion to fibrin, stabilizing the thrombus $[9,10]$. This interdependency supports a 'dual pathway' strategy targeting the coagulation cascade and the platelet component of thrombus formation.

Historical data confirm the efficacy of targeting the dual pathway in reducing ischemic events after ACS [11]. Meta-analysis data show that, versus acetylsalicylic acid (ASA) alone, ASA plus warfarin significantly reduced the risk of death, myocardial infarction (MI), or stroke in patients with an international normalized ratio of 2-3 $(p<0.0001)$. However, major bleeding risk was increased [11] and led to the restriction of combined anticoagulant and antiplatelet therapy to patients with ACS and a firm indication for oral anticoagulation, such as paroxysmal, persistent, or permanent atrial fibrillation (AF), and a $\mathrm{CHA}_{2} \mathrm{DS}_{2}-\mathrm{VASc}$ (Cardiac failure, Hypertension, Age $\geq 75$ [2 points], Diabetes, Stroke [2 points]-Vascular disease, Age 65-74, Sex category) score $\geq 2$ [12]. The long-term standard of care for antithrombotic treatment after ACS remains 'dual antiplatelet therapy' with potent $\mathrm{P} 2 \mathrm{Y}_{12}$ inhibitors (clopidogrel, prasugrel, and ticagrelor) plus ASA [12,13], based on trial data showing clinical benefit when added to ASA.

The first trial demonstrating clinical benefit was the CURE (Clopidogrel in Unstable Angina to Prevent Recurrent Events) trial, where addition of clopidogrel to various doses of ASA reduced the rate of cardiovascular death, MI, or stroke versus ASA alone. As might be expected, bleeding risk increased with increasing ASA dose [14].

Subsequent trials have demonstrated the superiority of prasugrel and ticagrelor over clopidogrel in reducing ischemic events, albeit with increased bleeding. The TRITON-TIMI 38 (TRial to Assess Improvement in Therapeutic Outcomes by Optimizing Platelet InhibitioN with Prasugrel-Thrombolysis In Myocardial Infarction 38) trial of $>13,000$ patients with ACS undergoing percutaneous coronary intervention (PCI) compared prasugrel and ASA with clopidogrel and ASA. The composite of cardiovascular death, non-fatal MI, or non-fatal stroke occurred in $9.9 \%$ of patients receiving prasugrel and in $12.1 \%$ receiving clopidogrel $(p<0.001)$. Non-coronary artery bypass graft (CABG)-related Thrombosis in MI (TIMI) major bleeding was more frequent with prasugrel $(2.4 \%$ vs. $1.8 \%$, respectively; $p=0.03$ ), as was fatal bleeding [15].

Vascular death, MI, or stroke occurred in 9.8\% of $>18,000$ patients with ACS in the PLATO (PLATelet inhibition and patient Outcome) trial administered ticagrelor plus ASA versus $11.7 \%$ treated with clopidogrel plus ASA $(p<0.001)$. Major bleeding rates between the groups were similar. However, non-CABG-related TIMI major bleeding was more frequent with ticagrelor $(2.8 \%$ vs. $2.2 \%$, respectively; $p=0.03$ ), as was fatal intracranial bleeding [16].

These studies established the role of $\mathrm{P}_{2} \mathrm{Y}_{12}$ inhibitors as the mainstay of antithrombotic therapy in ACS. However, although TRITON-TIMI 38 and PLATO showed superiority over clopidogrel in reducing post-ACS ischemic events, they revealed a residual risk of recurrent cardiovascular events and death of $\sim 10 \%$ despite 'optimal' dual antiplatelet therapy [17]. Therefore, new approaches to further reduce the residual risk of subsequent ischemic events, while minimizing bleeding risk, are required.

More recently, studies have explored novel therapeutic agents targeting different pathways of the coagulation cascade and adding a new agent to a dual antiplatelet regimen.
Fig. 1 Current concepts of the coagulation process (reproduced with permission from De Caterina et al. [6]). $A D P$ adenosine diphosphate, $G P$ glycoprotein, $P A R$ protein-activated receptor, $T F$ tissue factor, $v W F$ von Willebrand factor

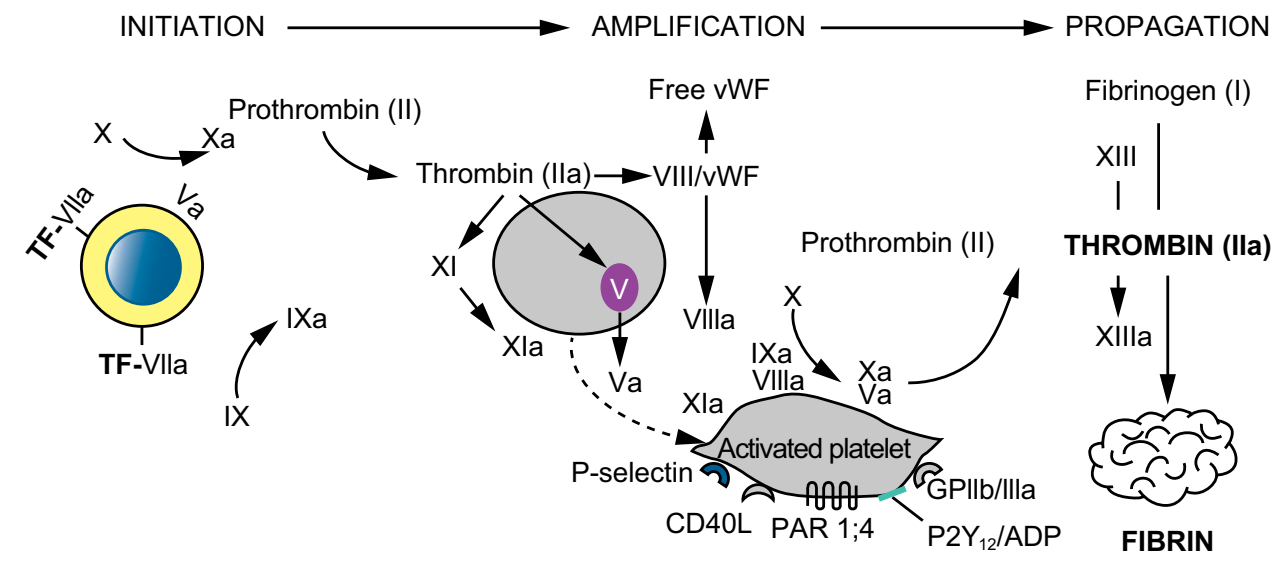


Table 1 Endpoints of the ATLAS ACS 2 TIMI 51, APPRAISE-2, RE-DEEM, RUBY-1, and AXIOM-ACS trials

\begin{tabular}{|c|c|c|}
\hline Trial & Ischemic events & Bleeding events \\
\hline $\begin{array}{l}\text { ATLAS ACS } 2 \text { TIMI } 51 \\
\text { [22] }\end{array}$ & $\begin{array}{l}\text { CV death, MI, or stroke: } 9.1 \% \text { with rivaroxaban } \\
2.5 \mathrm{mg} \text { bid vs. } 10.7 \% \text { with placebo }(p=0.02)^{\mathrm{a}}\end{array}$ & $\begin{array}{l}\text { Non-CABG-related bleeding: } 1.8 \% \text { with rivaroxaban } 2.5 \mathrm{mg} \text { bid } \\
\text { vs. } 0.6 \% \text { with placebo }(p<0.001)^{\mathrm{a}} \\
\text { Intracranial hemorrhage: } 0.4 \% \text { with rivaroxaban } 2.5 \mathrm{mg} \text { bid vs. } \\
0.2 \% \text { with placebo }(p=0.04)^{\mathrm{a}}\end{array}$ \\
\hline APPRAISE-2 [19] & $\begin{array}{l}\mathrm{CV} \text { death, MI, or ischemic stroke: } 7.5 \% \text { with } \\
\text { apixaban vs. } 7.9 \% \text { with placebo }(p=\mathrm{NS})\end{array}$ & $\begin{array}{l}\text { Major bleeding: } 1.3 \% \text { with apixaban vs. } 0.5 \% \text { with placebo } \\
(p=0.001)\end{array}$ \\
\hline RE-DEEM [23] & $\begin{array}{l}\text { CV death, non-fatal MI, or non-hemorrhagic } \\
\text { stroke: } 4.6,4.9,3.0 \text {, and } 3.5 \% \text { with dabigatran } \\
50,75,110 \text {, and } 150 \mathrm{mg} \text { bid, respectively, vs. } \\
3.8 \% \text { with placebo }\end{array}$ & $\begin{array}{l}\text { Major or clinically relevant minor bleeding: } 3.5,4.3,7.9 \text {, and } \\
7.8 \% \text { with dabigatran } 50,75,110 \text {, and } 150 \mathrm{mg} \text { bid, respectively, } \\
\text { vs. } 2.2 \% \text { with placebo }(p<0.001 \text { for dabigatran } 110 \text { and } 150 \mathrm{mg} \\
\text { bid vs. placebo })^{\mathrm{a}}\end{array}$ \\
\hline RUBY-1 [20] & $\begin{array}{l}\text { All-cause death, non-fatal MI, non-fatal stroke, or } \\
\text { severe recurrent ischemia: } 6.5 \% \text { with darexaban } \\
\text { vs. } 5.2 \% \text { with placebo }{ }^{\mathrm{a}}\end{array}$ & $\begin{array}{l}\text { Major or clinically relevant non-major bleeding: } 5.6-7.3 \% \text { (od) } \\
\text { and } 6.8-11.3 \% \text { (bid) with darexaban } 10-60 \mathrm{mg} / \text { day vs. } 3.1 \% \\
\text { with placebo (overall } p=0.02)^{\mathrm{a}}\end{array}$ \\
\hline AXIOM-ACS [21] & $\begin{array}{l}\text { CV death, non-fatal MI, non-fatal stroke, or myo- } \\
\text { cardial ischemia requiring hospitalization: } 4.8 \% \\
\text { with letaxaban } 20-240 \mathrm{mg} / \text { day vs. } 4.4 \% \text { with } \\
\text { placebo ( } p=\mathrm{NS} \text { ) }\end{array}$ & $\begin{array}{l}\text { TIMI major bleeding: } 0.9 \% \text { with letaxaban } 20-240 \mathrm{mg} / \text { day vs. } \\
0.5 \% \text { with placebo }(p=\mathrm{NS})\end{array}$ \\
\hline
\end{tabular}

bid twice daily, $C A B G$ coronary artery bypass grafting, $C V$ cardiovascular, $M I$ myocardial infarction, $N S$ not significant, od once daily, $T I M I$ thrombolysis in myocardial infarction

${ }^{a}$ Kaplan-Meier estimates

Vorapaxar, a protease-activated receptor-1 antagonist, inhibits thrombin-induced platelet aggregation. In the phase III TRACER (Thrombin Receptor Antagonist for Clinical Event Reduction in Acute Coronary Syndrome) trial, 12,944 patients with ACS received vorapaxar or placebo plus standard antiplatelet therapy, predominantly clopidogrel plus ASA [18]. Vorapaxar increased moderate or severe bleeding $(7.2 \%$ vs. $5.2 \% ; p<0.001)$ and intracranial bleeding $(1.1 \%$ vs. $0.2 \% ; p<0.001)$ in GUSTO (Global Utilization of Streptokinase and t-PA [tissue plasminogen activator] for Occluded Coronary Arteries), without improving ischemic outcomes. The composite of cardiovascular death, MI, stroke, recurrent ischemia with rehospitalization, or urgent coronary revascularization was not significantly reduced with vorapaxar (18.5\% vs. $19.9 \% ; p=0.07)$ [18].

Several non-vitamin K antagonist (VKA) oral anticoagulants (NOACs), including apixaban, darexaban, letaxaban, and rivaroxaban (direct Factor Xa inhibitors) and dabigatran (a direct thrombin inhibitor), have been evaluated in post-ACS, secondary prevention trials. The APPRAISE-2 (Apixaban for Prevention of Acute Ischaemic Events-2) [19], RUBY-1 [20], AXIOM-ACS [21], ATLAS ACS 2 TIMI 51 (Anti-Xa Therapy to Lower Cardiovascular Events in Addition to Aspirin With or Without Thienopyridine Therapy in Subjects with Acute Coronary Syndrome-Thrombolysis in Myocardial Infarction 51) [22], and RE-DEEM [23] trials tested these agents in combination with dual antiplatelet therapy (Table 1).
The phase III ATLAS ACS 2 TIMI 51 trial [22] randomized over 15,500 patients with ACS to receive rivaroxaban 2.5 or $5 \mathrm{mg}$ twice daily (doses based on phase II ATLAS ACS TIMI 46 trial [24]) or placebo in addition to ASA with or without clopidogrel or ticlopidine in accordance with local guidelines. The findings led to approval of rivaroxaban in Europe in combination with ASA alone or ASA and clopidogrel (or ticlopidine) in selected patients with ACS at low risk of bleeding; rivaroxaban remains the only NOAC currently approved for this indication [12].

In contrast, other trials [19-21, 23] with NOACs in a triple therapy regimen failed to show net clinical benefit. The phase III APPRAISE-2 trial aimed to investigate the efficacy and safety of apixaban in addition to standard antiplatelet therapy in patients with a recent ACS and at least two additional risk factors for ischemic events. The trial was terminated early because apixaban $5 \mathrm{mg}$ twice daily plus antiplatelet therapy led to an increase in the number of major bleeding events in this patient population, without a significant reduction in recurrent ischemic events [19]. These NOAC trials demonstrate the need for 'optimal balance' between reducing ischemic events and increasing bleeding risk when combining anticoagulant and antiplatelet therapies in patients with ACS.

The phase II GEMINI-ACS-1 trial took a different approach to secondary prevention and compared rivaroxaban $2.5 \mathrm{mg}$ twice daily plus a P2 $\mathrm{Y}_{12}$ inhibitor with ASA plus a $\mathrm{P} 2 \mathrm{Y}_{12}$ inhibitor in patients with ACS [25]. The risk of TIMI non-CABG clinically significant bleeding was similar in both trial arms. The rate of the exploratory endpoint of 
the composite of cardiovascular death, MI, stroke, or definite stent thrombosis was also similar between the treatment arms.

The role of ASA has been questioned because of concerns over increased bleeding with triple therapy. WOEST (What is the Optimal antiplatElet and anticoagulant therapy in patients with oral anticoagulation and coronary StenTing), a small-scale, open-label study [26], compared clopidogrel alone (dual therapy) with clopidogrel plus ASA (triple therapy) in patients already receiving long-term oral anticoagulation who had undergone PCI [26]. Compared with triple therapy, dual therapy had a lower rate of any bleeding (19.4\% vs. $44.4 \% ; p<0.0001)$ and a lower rate of death, MI, stroke, target vessel revascularization, or stent thrombosis (11.1\% vs. $17.6 \% ; p=0.025)$ [26]. A large meta-analysis was conducted to compare the safety and efficacy of dual therapy with triple therapy in patients on oral anticoagulants undergoing PCI, and obtained similar findings to the WOEST study; there was an increased risk of major bleeding events with triple therapy compared with dual therapy [27]. The WOEST 2 registry (ClinicalTrials.gov identifier NCT02635230) plans to recruit 2200 patients with AF undergoing coronary revascularization, treated with an oral anticoagulant and a P2 $\mathrm{Y}_{12}$ inhibitor with or without ASA, with completion scheduled for 2019. Despite its limitations, WOEST was the first study to suggest that combining an anticoagulant with a $\mathrm{P} 2 \mathrm{Y}_{12}$ inhibitor alone may be suitable for long-term secondary prevention after an ACS event in patients with no prior indication for long-term anticoagulant therapy such as AF.

In the PIONEER AF-PCI (Prevention of Bleeding in Patients with Atrial Fibrillation Undergoing PCI) trial [28] of patients with AF undergoing PCI, over $50 \%$ of patients had a history of ACS in the preceding 12 months (Fig. 2). This study confirmed the safety, in terms of reduced TIMI major and minor bleeding, of rivaroxaban $2.5 \mathrm{mg}$ twice daily with dual antiplatelet therapy and rivaroxaban $15 \mathrm{mg}$ once daily with single antiplatelet therapy versus warfarin plus dual antiplatelet therapy. The trial was not powered to show superiority or non-inferiority for the reduction in major adverse cardiovascular events. Following the PIONEER AF-PCI trial, up to 12 months' treatment with rivaroxaban $15 \mathrm{mg}$ once daily (or $10 \mathrm{mg}$ once daily in patients with moderate renal impairment) plus a $\mathrm{P} 2 \mathrm{Y}_{12}$ inhibitor was approved by the European Medicines Agency for use in patients with non-valvular AF who undergo PCI with stent placement; however, the approval document highlighted that data in this population were limited and no data were available in such patients with a history of stroke or transient ischemic attack [29].

Similarly, the RE-DUAL PCI (Dual Antithrombotic Therapy with Dabigatran after PCI in Atrial Fibrillation) trial compared two dabigatran-based (110 or $150 \mathrm{mg}$ twice daily) dual antithrombotic therapy regimens with warfarin-based triple therapy in patients with AF after PCI (Fig. 3) [30]. Dabigatran plus a $\mathrm{P} 2 \mathrm{Y}_{12}$ inhibitor was associated with a significantly lower rate of major or clinically relevant non-major bleeding than warfarin plus a $\mathrm{P} 2 \mathrm{Y}_{12}$ inhibitor plus ASA. The trial also found that when data from both dabigatran arms were pooled, the dual-therapy regimens were non-inferior to the triple-therapy regimen in terms of efficacy.

European guidance supports triple therapy for the shortest time possible for patients with ACS and AF undergoing PCI [12, 31]. Furthermore, European guidelines on the use of dual antiplatelet therapy in coronary artery disease state that dual therapy with clopidogrel and an oral anticoagulant should be considered in place of triple therapy when a patient with an indication for anticoagulation has a bleeding risk that outweighs their ischemic risk [31]. However, these recommendations are based partly on expert opinion, because prospective studies of triple therapy in these patients are limited, although further trials are currently recruiting (Table 2).

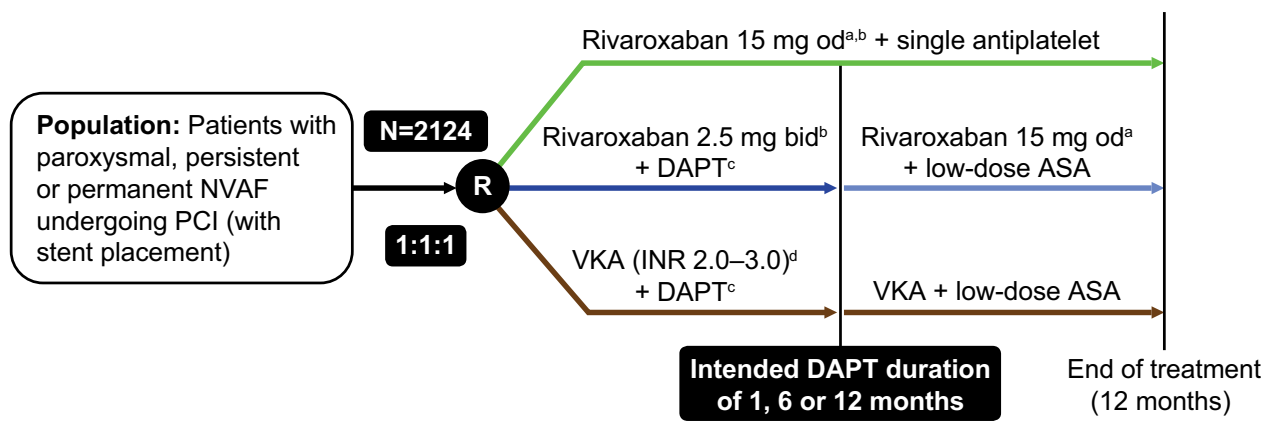

Fig. 2 Design of the PIONEER AF-PCI trial [42]. ${ }^{\text {aCCreatinine clear- }}$ ance $30-49 \mathrm{~mL} / \mathrm{min}: 10 \mathrm{mg}$ od. ${ }^{\mathrm{b}}$ First dose $72-96 \mathrm{~h}$ after sheath removal. ${ }^{\mathrm{c} A S A}(75-100 \mathrm{mg} /$ day) plus clopidogrel $(75 \mathrm{mg} /$ day) (alternative use of prasugrel or ticagrelor allowed, but capped at $15 \%$ ). ${ }^{\mathrm{d}}$ First dose $12-72 \mathrm{~h}$ after sheath removal. ASA acetylsalicylic acid, bid twice daily, DAPT dual antiplatelet therapy, INR international normalized ratio, NVAF non-valvular atrial fibrillation, od once daily, $P C I$ percutaneous coronary intervention, $R$ randomization, $V K A$ vitamin $\mathrm{K}$ antagonist 


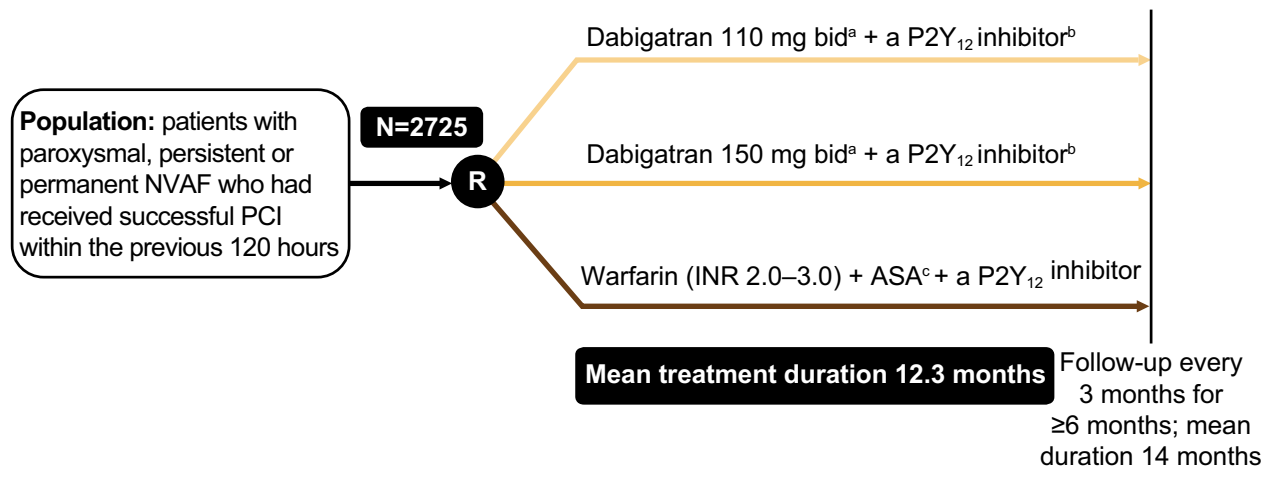

Fig. 3 Design of the RE-DUAL PCI trial [30]. Non-US patients aged $\geq 80$ years and Japanese patients aged $\geq 70$ years were randomized to receive dabigatran $110 \mathrm{mg}$ bid dual therapy or warfarinbased triple therapy in accordance with the respective product labels in these countries. a First dose within $120 \mathrm{~h}$ after PCI. ${ }^{\mathrm{b}}$ Clopidogrel (75 mg od) or ticagrelor (90 mg bid) for at least 12 months after

\section{Discussion and Future Perspectives}

The development of NOACs, which have demonstrated fewer intracranial bleeding events and deaths than VKAs in AF trials [32], has renewed interest in a dual pathway strategy for the secondary prevention of ACS, targeting both the coagulation cascade and the platelet component of thrombus formation [7, 33].

The disparate outcomes of the only two phase III trials (ATLAS ACS 2 TIMI 51 and APPRAISE-2) conducted to date in patients with ACS deserve further discussion. The apixaban dose in APPRAISE-2 was the same as that recommended for use in patients with AF, whereas the rivaroxaban dose in ATLAS ACS 2 TIMI 51 was adjusted to $25-50 \%$ of the AF dose [22]. The lower rivaroxaban randomization. ${ }^{\mathrm{c}} \mathrm{ASA} \leq 100 \mathrm{mg}$ od was stopped at 1 or 3 months in patients who received bare-metal stent or drug-eluting stent implantation, respectively. ASA acetylsalicylic acid, bid twice daily, INR international normalized ratio, $N V A F$ non-valvular atrial fibrillation, od once daily, $P C I$ percutaneous coronary intervention, $R$ randomization

dose ( $2.5 \mathrm{mg}$ twice daily) exhibited the best efficacy and safety profile [22].

The importance of dose selection for patients with ACS may be partly explained by the 'dual property' of thrombin. Thrombin is anticoagulatory at low concentrations but a procoagulant at high concentrations, a scenario known as the 'thrombin paradox' [34]. The GUSTO IIb trial of patients with ACS showed elevated thrombin generation in the 12 months post index event [8]. However, the correlation between thrombin generation and clinical events was non-linear, with higher rates of cardiac death or MI seen at both very low and very high thrombin levels, complicating the search for an optimal post-ACS anticoagulant dose [34].

In addition, compared with ATLAS ACS 2 TIMI 51, APPRAISE-2 patients were older and more likely to have diabetes mellitus and/or renal dysfunction, and

Table 2 Ongoing trials in patients with atrial fibrillation undergoing percutaneous coronary intervention

\begin{tabular}{|c|c|c|}
\hline Trial details & AUGUSTUS & ENTRUST AF-PCI \\
\hline ClinicalTrials.gov identifier & NCT02415400 & NCT02866175 \\
\hline Study phase & IV & III \\
\hline Patient population & $\mathrm{AF}+\mathrm{ACS}$ or PCI with stenting & $\mathrm{AF}+\mathrm{PCI}$ with stenting \\
\hline \multirow[t]{2}{*}{ Interventions } & Apixaban 2.5 or $5 \mathrm{mg}$ bid $+\mathrm{P}_{2} \mathrm{Y}_{12}$ inhibitor \pm ASA & $\begin{array}{l}\text { Edoxaban } 60 \mathrm{mg} \text { (or } 30 \mathrm{mg} \text { ) } \\
\text { od }+\mathrm{P} 2 \mathrm{Y}_{12} \text { inhibitor }\end{array}$ \\
\hline & $\mathrm{VKA}+\mathrm{P} 2 \mathrm{Y}_{12}$ inhibitor $\pm \mathrm{ASA}$ & $\mathrm{VKA}+\mathrm{P}_{2} \mathrm{Y}_{12}$ inhibitor $+\mathrm{ASA}^{\mathrm{a}}$ \\
\hline Primary endpoint & Major or CRNM bleeding & Major or CRNM bleeding \\
\hline Secondary endpoints & Death, ischemic events & Death, ischemic events \\
\hline Target enrollment $(n)$ & 4600 & 1500 \\
\hline Expected completion & December 2018 & November 2018 \\
\hline
\end{tabular}

$A C S$ acute coronary syndrome, $A F$ atrial fibrillation, $A S A$ acetylsalicylic acid, bid twice daily, $C R N M$ clinically relevant non-major, $o d$ once daily, $P C I$ percutaneous coronary intervention, $V K A$ vitamin $\mathrm{K}$ antagonist

${ }^{a}$ ASA for 1-12 months guided by clinical presentation 
non-ST-elevation MI versus ST-elevation MI as their index event $[19,22,33]$. Furthermore, ATLAS ACS 2 TIMI 51 excluded patients with prior stroke or transient ischemic attack who were already receiving ASA plus a $\mathrm{P} 2 \mathrm{Y}_{12}$ inhibitor $[22,33]$. The higher-risk population of APPRAISE-2 may have been less responsive to anticoagulant therapy than the ATLAS ACS 2 TIMI 51 population [22, 33].

The benefit-risk profile of dabigatran in patients with ACS can only be determined in an adequately powered phase III trial. To date, no such trial has been scheduled; however, the two highest dabigatran doses used in the phase II RE-DEEM trial significantly increased major and clinically relevant minor bleeding, and were identical to those used in patients with AF [23, 33].

The recently completed PIONEER AF-PCI [28] and RE-DUAL PCI [35] trials and the ongoing AUGUSTUS (NCT02415400) and ENTRUST AF-PCI (NCT02866175) trials should help to determine the treatment regimens with the optimal benefit-risk profile in patients with ACS and AF. The trials will also provide additional information on the appropriate duration of antiplatelet therapy and intensity of oral anticoagulation in patients with ACS and AF [28], and on the feasibility of removing ASA from the treatment regimen [33].

Most patients with ACS have co-morbidities and risk factors that put them at increased risk of ischemic or bleeding events [36]. Therefore, individualized assessment of bleeding risk and risk of coronary stent thrombosis are important considerations in guiding the duration of triple therapy [12, $31,37,38]$ and stent type in patients requiring PCI.

Renal impairment occurs in approximately $30-40 \%$ of patients with ACS and is an independent predictor of increased mortality and major bleeding [36]. Although the same antiplatelet regimens are recommended regardless of renal function status, dose adjustments of oral anticoagulants are usually recommended for those with moderate renal impairment $[12,37]$. Dabigatran is unlikely to be the first-choice NOAC in patients with moderate renal impairment because it is primarily excreted via the kidneys [37]. Minimal data are available in patients with severe renal impairment, and no prospective data exist for patients with end-stage renal disease or who are on hemodialysis [37].

Diabetes is present in $20-30 \%$ of patients with ACS and is an independent predictor of mortality $[12,36]$. Although guidelines recommend that patients with diabetes receive the same antithrombotic regimens as those without diabetes [12], treatment of this patient population remains suboptimal [36]. In a subanalysis, TRITON-TIMI 38, patients with diabetes received a greater net clinical benefit from prasugrel versus clopidogrel than non-diabetic patients [39]. However, no such interaction with diabetic status was found in the PLATO trial with ticagrelor [40] or ATLAS ACS 2 TIMI 51 with rivaroxaban [22].
Female sex is a predictor of major bleeding in ACS, and women have an increased risk of recurrence of ischemic events at 6 months [36]. Current guidelines recommend that men and women with ACS are managed similarly; however, some studies have suggested that women are less likely to receive evidence-based care [12].

Patients aged $\geq 75$ years with ACS have an increased risk of recurrent ischemic events, bleeding, and mortality, with $60 \%$ of all ACS-related deaths occurring in this age group [41]. However, again, they are less likely to receive evidence-based therapies [12]. Although prasugrel is generally not recommended in elderly patients after TRITON-TIMI 38 did not find a net clinical benefit in this age group [15], the PLATO trial [41] did not find significant differences in efficacy and safety in elderly patients receiving ticagrelor. Guidelines recommend that close attention be paid to specific contraindications in elderly patients, as well as renal function. Individualized benefit-risk assessments in this age group should take account of estimated life expectancy, co-morbidities, quality of life, and patient preferences [12].

\section{Conclusion}

Despite optimal secondary prevention after ACS, a residual ongoing risk of recurrent ischemic events remains up to and beyond 12 months. Trials of triple therapy (oral anticoagulant plus dual antiplatelet therapy) targeting the dual pathway have shown reduced ischemic events, albeit at an increased risk of bleeding. Ongoing studies are focusing on dual therapy (oral anticoagulant plus single antiplatelet therapy) to target the platelet- and fibrin-mediated pathways of thrombus formation for ACS secondary prevention. Several trials are underway, particularly in patients with concomitant $\mathrm{AF}$, and will provide important data on the optimal intensity of oral anticoagulation, the optimal antiplatelet therapy regimen, the use of oral anticoagulation combined with new P2 $\mathrm{Y}_{12}$ inhibitors, and the efficacy and safety of NOACs versus VKAs. Many patients with ACS have co-morbidities, which require consideration to enable optimal treatment and long-term outcomes. The addition of anticoagulation may enable an individualized approach to the use of antithrombotic agents for secondary prevention of ACS. Algorithms to simplify choice between the increased treatment options may help clinicians assess benefits and risks of each treatment strategy and balance the risk of thrombotic events with the risk of bleeding [36].

Acknowledgements The authors would like to acknowledge Ngaire White (Chameleon Communications Ltd), who provided editorial support with funding from Bayer AG. 


\section{Compliance with Ethical Standards}

Funding Editorial assistance for the preparation of this manuscript was funded by Bayer AG.

Conflict of interest Sudhakar George, Eunice NC Onwordi, Amr Gamal, and Azfar Zaman declare that they have no conflicts of interest.

Open Access This article is distributed under the terms of the Creative Commons Attribution-NonCommercial 4.0 International License (http://creativecommons.org/licenses/by-nc/4.0/), which permits any noncommercial use, distribution, and reproduction in any medium, provided you give appropriate credit to the original author(s) and the source, provide a link to the Creative Commons license, and indicate if changes were made.

\section{References}

1. Johnston SS, Curkendall S, Makenbaeva D, et al. The direct and indirect cost burden of acute coronary syndrome. J Occup Environ Med. 2011;53:2-7.

2. Nichols M, Townsend N, Scarborough P, et al. Cardiovascular disease in Europe 2014: epidemiological update. Eur Heart J. 2014;35:2950-9.

3. Taylor MJ, Scuffham PA, McCollam PL, et al. Acute coronary syndromes in Europe: 1-year costs and outcomes. Curr Med Res Opin. 2007;23:495-503.

4. Alnasser SMA, Huang W, Gore JM, et al. Late consequences of acute coronary syndromes: Global Registry of Acute Coronary Events (GRACE) follow-up. Am J Med. 2015;128:766-75.

5. Fox KAA, Carruthers KF, Dunbar DR, et al. Underestimated and under-recognized: the late consequences of acute coronary syndrome (GRACE UK-Belgian Study). Eur Heart J. 2010;31:2755-64.

6. De Caterina R, Husted S, Wallentin L, et al. General mechanisms of coagulation and targets of anticoagulants (Section I). Position paper of the ESC working group on thrombosis-task force on anticoagulants in heart disease. Thromb Haemost. 2013;109:569-79.

7. White H. Targeting therapy to the fibrin-mediated pathophysiology of acute coronary syndrome. Clin Appl Thromb Hemost. 2014;20:516-23.

8. Ardissino D, Merlini PA, Bauer KA, et al. Coagulation activation and long-term outcome in acute coronary syndromes. Blood. 2003;102:2731-5.

9. Esmon CT. Crosstalk between inflammation and thrombosis. Maturitas. 2008;61:122-31.

10. Tamura N, Kitajima I, Kawamura Y, et al. Important regulatory role of activated platelet-derived procoagulant activity in the propagation of thrombi formed under arterial blood flow conditions. Circ J. 2009;73:540-8.

11. Andreotti F, Testa L, Biondi-Zoccai GG, et al. Aspirin plus warfarin compared to aspirin alone after acute coronary syndromes: an updated and comprehensive meta-analysis of 25,307 patients. Eur Heart J. 2006;27:519-26.

12. Roffi M, Patrono C, Collet JP, et al. ESC Scientific Document Group 2015 ESC guidelines for the management of acute coronary syndromes in patients presenting without persistent STsegment elevation: Task Force for the Management of Acute Coronary Syndromes in Patients Presenting without Persistent ST-Segment Elevation of the European Society of Cardiology (ESC). Eur Heart J. 2016;37:267-315.
13. Steg PG, James SK, Atar D, et al. ESC guidelines for the management of acute myocardial infarction in patients presenting with ST-segment elevation: the task force on the management of ST-segment elevation acute myocardial infarction of the European Society of Cardiology (ESC). Eur Heart J. 2012;33:2569-619.

14. Peters RJ, Mehta SR, Fox KA, et al. Effects of aspirin dose when used alone or in combination with clopidogrel in patients with acute coronary syndromes. Observations from the Clopidogrel in Unstable angina to prevent Recurrent Events (CURE) study. Circulation. 2003;108:1682-7.

15. Wiviott SD, Braunwald E, McCabe $\mathrm{CH}$, et al. Prasugrel versus clopidogrel in patients with acute coronary syndromes. N Engl J Med. 2007;357:2001-15.

16. Wallentin L, Becker RC, Budaj A, et al. Ticagrelor versus clopidogrel in patients with acute coronary syndromes: supplementary appendix. N Engl J Med. 2009;361:1045-57.

17. Stachon P, Ahrens I, Bode C, et al. Dual pathway therapy in acute coronary syndrome. J Thromb Thrombolysis. 2016;42:254-60.

18. Tricoci P, Huang Z, Held C, et al. Thrombin-receptor antagonist vorapaxar in acute coronary syndromes. N Engl J Med. 2012;366:20-33.

19. Alexander JH, Lopes RD, James S, et al. Apixaban with antiplatelet therapy after acute coronary syndrome. N Engl J Med. 2011;365:699-708.

20. Steg PG, Mehta SR, Jukema JW, et al. RUBY-1: a randomized, double-blind, placebo-controlled trial of the safety and tolerability of the novel oral factor Xa inhibitor darexaban (YM150) following acute coronary syndrome. Eur Heart J. 2011;32:2541-54.

21. Goldstein S, Bates ER, Bhatt DL, et al. Phase 2 study of TAK-442, an oral Factor Xa inhibitor, in patients following acute coronary syndrome. Thromb Haemost. 2014;111:1141-52.

22. Mega JL, Braunwald E, Wiviott SD, et al. Rivaroxaban in patients with a recent acute coronary syndrome. N Engl J Med. 2012;366:9-19.

23. Oldgren J, Budaj A, Granger CB, et al. Dabigatran vs. placebo in patients with acute coronary syndromes on dual antiplatelet therapy: a randomized, double-blind, phase II trial. Eur Heart J. 2011;32:2781-9.

24. Mega JL, Braunwald E, Mohanavelu S, et al. Rivaroxaban versus placebo in patients with acute coronary syndromes (ATLAS ACS-TIMI 46): a randomised, double-blind, phase II trial. Lancet. 2009;374:29-38.

25. Ohman EM, Roe MT, Steg PG, et al. Clinically significant bleeding with low-dose rivaroxaban versus aspirin, in addition to P2Y12 inhibition, in acute coronary syndromes (GEMINIACS-1): a double-blind, multicentre, randomised trial. Lancet. 2017;389:1799-808.

26. Dewilde WJ, Oirbans T, Verheugt FW, et al. Use of clopidogrel with or without aspirin in patients taking oral anticoagulant therapy and undergoing percutaneous coronary intervention: an openlabel, randomised, controlled trial. Lancet. 2013;381:1107-15.

27. D'Ascenzo F, Taha S, Moretti C, et al. Meta-analysis of randomized controlled trials and adjusted observational results of use of clopidogrel, aspirin, and oral anticoagulants in patients undergoing percutaneous coronary intervention. Am J Cardiol. 2015;115:1185-93.

28. Gibson CM, Mehran R, Bode C, et al. Prevention of bleeding in patients with atrial fibrillation undergoing PCI. N Engl J Med. 2016;375:2423-34.

29. Bayer AG. Xarelto ${ }^{\circledR}$ (rivaroxaban) summary of product characteristics. 2018. http://www.ema.europa.eu/docs/en_GB/document_ library/EPAR_-_Product_Information/human/000944/WC500 057108.pdf. Accessed 21 May 2018. 
30. Cannon CP, Bhatt DL, Oldgren J, et al. Dual antithrombotic therapy with dabigatran after PCI in atrial fibrillation. N Engl J Med. 2017;377:1513-24.

31. Valgimigli M, Bueno H, Byrne RA, et al. 2017 ESC focused update on dual antiplatelet therapy in coronary artery disease developed in collaboration with EACTS: the task force for dual antiplatelet therapy in coronary artery disease of the European Society of Cardiology (ESC) and of the European Association for Cardio-Thoracic Surgery (EACTS). Eur Heart J. 2018;39:213-60.

32. Ruff CT, Giugliano RP, Braunwald E, et al. Comparison of the efficacy and safety of new oral anticoagulants with warfarin in patients with atrial fibrillation: a meta-analysis of randomised trials. Lancet. 2014;383:955-62.

33. De Caterina R, Husted S, Wallentin L, et al. Oral anticoagulants in coronary heart disease (Section IV). Position paper of the ESC working group on thrombosis-task force on anticoagulants in heart disease. Thromb Haemost. 2016;115:685-711.

34. Bassand JP. Novel oral anticoagulants in acute coronary syndrome: re-evaluating the thrombin hypothesis. EuroIntervention. 2014;9:1333-41.

35. Cannon CP, Gropper S, Bhatt DL, et al. Design and rationale of the RE-DUAL PCI trial: a prospective, randomized, phase $3 \mathrm{~b}$ study comparing the safety and efficacy of dual antithrombotic therapy with dabigatran etexilate versus warfarin triple therapy in patients with nonvalvular atrial fibrillation who have undergone percutaneous coronary intervention with stenting. Clin Cardiol. 2016;39:555-64.

36. Husted $\mathrm{S}$. Antithrombotic therapy for long-term secondary prevention of acute coronary syndrome in high-risk patients. Ther Clin Risk Manag. 2015;11:263-77.
37. Heidbuchel H, Verhamme P, Alings M, et al. Updated European Heart Rhythm Association practical guide on the use of nonvitamin $\mathrm{K}$ antagonist anticoagulants in patients with non-valvular atrial fibrillation. Europace. 2015;17:1467-507.

38. Kirchhof P, Benussi S, Kotecha D, et al. 2016 ESC Guidelines for the management of atrial fibrillation developed in collaboration with EACTS. Eur Heart J. 2016;37:2893-962.

39. Wiviott SD, Braunwald E, Angiolillo DJ, et al. Greater clinical benefit of more intensive oral antiplatelet therapy with prasugrel in patients with diabetes mellitus in the trial to assess improvement in therapeutic outcomes by optimizing platelet inhibition with prasugrel-thrombolysis in myocardial infarction 38. Circulation. 2008;118:1626-36.

40. James S, Angiolillo DJ, Cornel JH, et al. Ticagrelor vs. clopidogrel in patients with acute coronary syndromes and diabetes: a substudy from the PLATelet inhibition and patient Outcomes (PLATO) trial. Eur Heart J. 2010;31:3006-16.

41. Husted S, James S, Becker RC, et al. Ticagrelor versus clopidogrel in elderly patients with acute coronary syndromes: a substudy from the prospective randomized PLATelet inhibition and patient Outcomes (PLATO) trial. Circ Cardiovasc Qual Outcomes. 2012;5:680-8.

42. Gibson CM, Mehran R, Bode C, et al. An open-label, randomized, controlled, multicenter study exploring two treatment strategies of rivaroxaban and a dose-adjusted oral vitamin $\mathrm{K}$ antagonist treatment strategy in subjects with atrial fibrillation who undergo percutaneous coronary intervention (PIONEER AF-PCI). Am Heart J. 2015;169(472-8):e5 